\title{
Public Lecture: Thinking about Oil: Energy Epistemologies and Political Futures
}

\author{
Professor Imre Szeman is a Canada \\ Research Ghair in Gultural Studies and \\ a Professor of English, Film Studies and \\ Sociology at the University of Alberta. \\ He conducts research on and teaches in \\ the areas of energy and environmental \\ studies, social and cultural theory, \\ globalization and nationalism, and \\ Ganadian studies. His publications \\ include Contemporary Literary and \\ Cultural Theory: The Johns Hopkins \\ Guide (2012) After Globalization (2011) \\ Gultural Theory: An Anthology (2010); \\ Cultural Autonomy: Frictions and \\ Connections (2010)
}

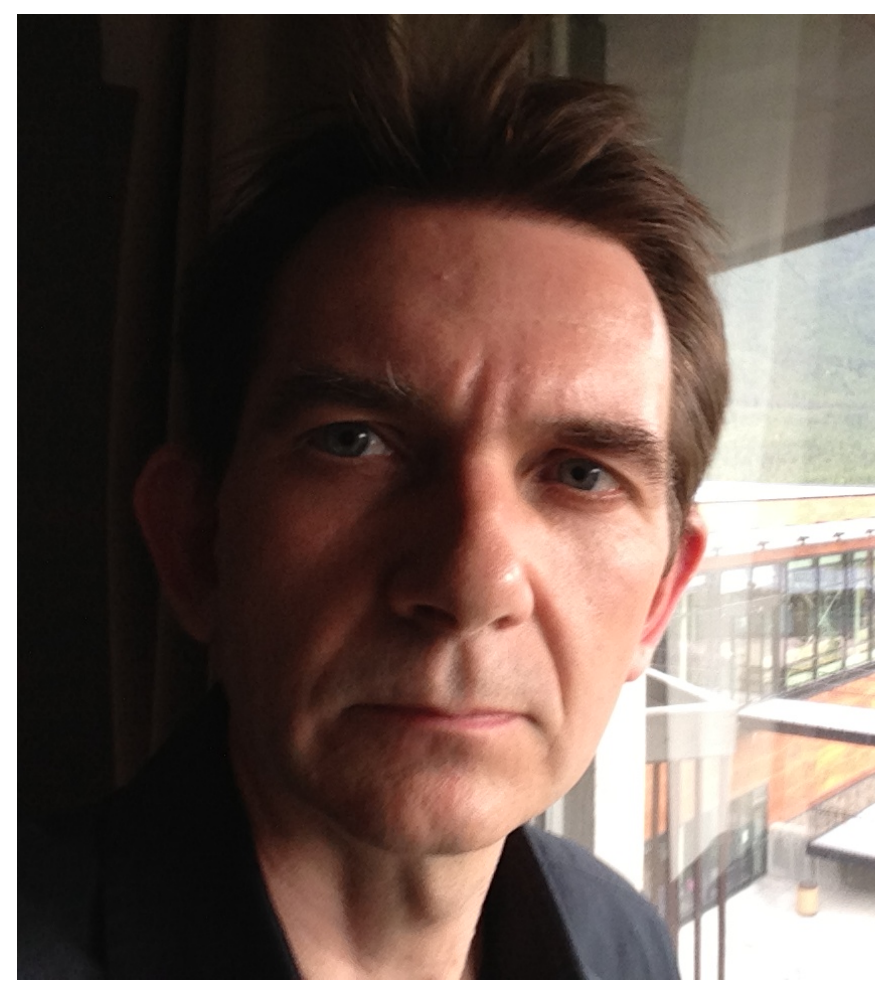

Monday Jan. 12, 2015 5:00-7:00pm

\section{Room HC 1600}

\section{Harbour Centre}

Simon Fraser University

515 W. Hastings St.

Coast Salish Territories/ Vancouver

All are welcome to join the lecture and discussion
As a contribution to the growing exploration of oil and energy in the humanities, I want to consider what we might learn by paying attention to how we know oil-that is, the complex, myriad ways in which we try to name and narrate oil's social significance-in order to better understand the opportunities and challenges of making oil and energy a more conceptually powerful part of our social and cultural understandings.

The first of the energy epistemologies I examine, Timothy Mitchell's Carbon Democracy, reframes the history of left politics in relation to shifts in dominant forms of energy. The second, Edward Burtynsky's photo-series, Oil, identifies the deep social significance of oil through experiments in visual form. The third example of knowing oil and energy emerges I probe is the ongoing struggle over the representation of the Alberta oil sands in public and political debate and discussion. The intent of examining these three distinct attempts to know oil as an essential component of social, cultural, and political life is to see what lessons such energy epistemologies might have for a left politics committed to an energy transition that would both ameliorate environmental concerns and enable greater social justice. 